See discussions, stats, and author profiles for this publication at: https://www.researchgate.net/publication/281762767

Synthesis of $\mathrm{Al}$ and $\mathrm{Ag}$ nanoparticles through ultra-sonic dissociation of thermal evaporation deposited thin films for promising clinical applications as polymer nanocomposite

Article in Advanced Materials Letters · January 2015

DOI: 10.5185/amlett.2015.5625

7 authors, including:

Divya Bhatia

Sapienza University of Rome

9 PUBLICATIONS 15 CITATIONS

SEE PROFILE

Some of the authors of this publication are also working on these related projects: 


\section{Synthesis of Al \& Ag Nanoparticles Through Ultra-Sonic Dissociation of Thermal Evaporation Deposited Thin Films for Promising Clinical Applications as Polymer Nanocomposite}

\section{Narendra Kumar Agrawal $^{1^{*}}$, Ravi Agarwal ${ }^{2}$, Divya Bhatia ${ }^{2}$, Divya Saxena ${ }^{2}$, Garima Kedawat ${ }^{3}$, K.C.Swami ${ }^{1}$, Y.K.Vijay,}

${ }^{1}$ Department of Physics, Malaviya National Institute of Technology, Jaipur 302017, India

${ }^{2}$ Department of Physics, University of Rajasthan, Jaipur-302004, India

${ }^{3}$ Center for Converging Technologies, University of Rajasthan, Jaipur-302004, India

${ }^{4}$ Vivekananda Global University, Jaipur, 303012, India

*Corresponding author. Tel: (+91) 8824092710; E-mail: research.nka@gmail.com

Received: , Revised: and Accepted:

\section{ABSTRACT}

Nanoparticles (NPs) having well-defined shape, size and clean surface serve as ideal model system to investigate surface/interfacial reactions. Ag and Al NPs are receiving great interest due to their wide applications in bio-medical field, aerospace and space technology as combustible additives in propellants and hydrogen generation. Hence, in this study, we have synthesized Ag and Al NPs using an innovative approach of ultra-sonic dissociation of thin films. Phase and particle size distributions of the Ag and Al NPs have been determined by X-ray diffraction (XRD) and transmission electron microscopy (TEM). Thin film dissociation/dissolution mechanism, hence conversion into NPs has been characterized by SEM- scanning electron microscope. EDXA \& ICPMS have been performed for chemical analysis of NPs. Optical properties have been characterized by UV-Vis and PL spectroscopy. These NPs have also been investigated for their anti-bacterial activity against Escherichia coli bacteria. To the best of our knowledge, this is the first time when NPs has been synthesized by ultra-sonic dissociation of thin films. As an application, these NPs were used further for synthesis of nanocomposite polymer membranes, which show excellent activity against bio film formation. Copyright $@ 2015$ VBRI press.

Keywords: Ag \& Al Nanoparticles; antibacterial; sterilization; bio-film formation; TEM.

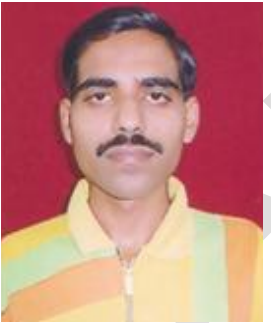

Narendra Kumar Agrawal received his M. Sc. in physics from Department of Physics, University of Rajasthan in 2009. Currently I have submitted his $\mathrm{Ph}$. D. thesis at Malaviya National Institute of Technology, Jaipur to award $\mathrm{Ph}$. D degree, under the supervision of Professor K. C. Swami and co- supervision of Professor Y. K. Vijay. My area of research includes Synthesis and enhancement of biocompatibility of bio-materials in controlled manner so that they can be used as biomedical devices or implants using the principles \& applications of Plasma Physics, Neuroscience, Nanotechnology, Biotechnology, Computer/Computational Science, Information technology.

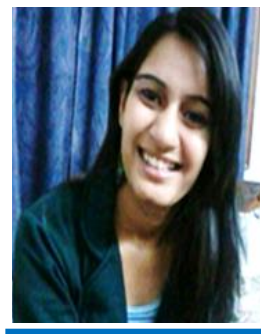

Divya Bhatia is pursuing her $M$. Tech. in Converging Technologies at University of Rajasthan, Rajasthan, India. Her major area of research includes Nanotechnology, Cognitive and Neuroscience. During her M. Tech., she has participated in more than five International Conferences. Currently she is also working as Research Assistant at Center for Neural and Cognitive Sciences at University of Hyderabad,
Hyderabad, India in the field of Psycholinguistics as she is interested in exploring the relationship of choice of language with executive control in Hindi-English Bilinguals in India.

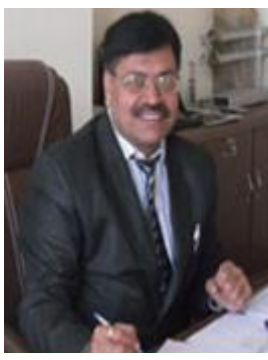

Y. K. Vijay received his M.Sc. degree in Physics and Ph.D. degree from University of Rajasthan, Jaipur (India) in 1975 and 1980 respectively. He was awarded Commonwealth and ICTP fellowships and spent one year in Uppsala University Sweden. Served as a Professor in Department of Physics, Director Centre for Development of Physics Education and Centre for Non-conventional Energy Resources at University of Rajasthan, Jaipur, India. His professional awards include: IUMRS Young Research, $\mathrm{R}$ K Ramanath, IAPT Teaching Aids Award. He has developed Electron Positron Accelerator, XRF, CVD and Positron Lifetime Spectrometer. His current research interests are polymer blends for organic photovoltaic cells, design and development of CNTs/Polymer composite based gas sensors and gas separation filters. At present he the working as President of Vivekananda Global University, Jaipur, India. 


\section{Introduction}

Silver (Ag) has an important part to develop world due to its novel electrical, optical and chemical properties, having significant applications in catalysis, optoelectronic materials, IC design, fuel cells, pigments and sensors [1-8]. While light weight, corrosion resistance, high reflectivity and thermal conductivity reflect importance of Aluminum (Al). Conversion of these metals to nano size materials is an efficient and reliable tool for enhancing their optical, physical, mechanical, chemical and catalytical properties, which opens up new fields of vast range applications in composite material fabrication, gas sensing, nonlinear optical devices, fuel cells, magnetic fluid and space science technology etc. [9-18].

The first instance of applications of silver nanoparticles (Ag NPs) dates back to 1857 when they were used to give a permanent, non-fading yellow and red color to church windows in Britain. Science than a large number of fields have been identified where silver NPs play significant role. These NPs are used to control infections \& spoilages, due to their well-known anti-bacterial, anti-fungal, anti-biotic properties and high toxicity for microbes. They are also used in microbial delivery vehicles targeting pest insects [1], bioactive product development [2], sensing and imaging [3], wound-healing [4], water-treatment [5], biomedicines, anti-fungal drugs [6], anti-plat-let agents [7], bio-sensors [19], textile industry [20], cosmetics, electronics and non-volatile memory applications [21] etc. Nano-silver based wall paints [22] are commercially available to prevent formation of algae and moulds on the inner and outer walls of buildings.

Aluminum nanoparticles (Al NPs), due to their high energy density are receiving great interest in the field of aerospace as combustible additives in Propellants [9], material synthesis [10], hydrogen generation [11], hydrogen storage [12] and solar cells applications [23]. Along with these advance applications, Al NPs have also revealed antimicrobial property [24] and show interaction with human epidermal keratinocytes shows variations in cytokine levels [25]. Al NPs can be used in biomaterials [13], catalyst support [14], dispersion-strengthening [15], heat-transfer fluids (suspensions) [16], packaging [17], transparent conductive coatings [18], wear-resistant [18] and additives in stable energetic materials [26].

There are numerous physical, chemical, biological and green approaches available for synthesis of different size and shape Ag NPs, such as small ceramic heater with a local heating source (100-200 nm) [27], laser ablation in water $(20-50 \mathrm{~nm})[\mathbf{2 0}, \mathbf{2 8}]$, dodecanethiol capped Ag NPs $(50-70 \mathrm{~nm})$ [29], ultraviolet irradiation photo-reduction technique at room temperature [30], pulsed sonoelectrochemical method [31], electrochemical reduction method at liquid/liquid interface of poly-phenylpyrrolecoated silver nanospheroids $(3-20 \mathrm{~nm})$ [32], green synthesis techniques $(50-200 \mathrm{~nm})$ [8], silver hydrosols (20$50 \mathrm{~nm}$ ) [33], bacterium Bacillus licheniformis culture (50 $\mathrm{nm}$ ) [34], combinational synthesis approach for formation of extracellular biosynthesis mono dispersed $\mathrm{Ag}$ nanoparticles $(5-50 \mathrm{~nm})$ [35] and extra cellular Ag NPs (5$50 \mathrm{~nm}$ ) using Fusarium oxysporum [36]. Al NPs can be synthesized by exploding wire technique (20-100nm) [37], wet chemical process $(85-200 \mathrm{~nm})$ [38], plasma laser ablation technique $(70-200 \mathrm{~nm})$ [39], inert gas evaporation $(10-50 \mathrm{~nm})$ [40], cryomelting process $(20-500 \mathrm{~nm})$ [41], electro explosion technique $(20-260 \mathrm{~nm})$ [42] and solution method $(65-500 \mathrm{~nm})$ [43]. Besides these above mentioned specific methods, these NPs can also be synthesized by using ball milling process, sol-gel method, chemical vapor deposition (CVD) and thermal spray method etc.

But any of these methods can't give control on particle size/particle size distribution during synthesis. Also mostly they have lengthy synthesis processes, surface coated with capping agents and generate toxic by-products. Hence even after few decayed of research on synthesis of these NPs, in a very recent report/research published in Nature Latter by Anil Desireddy et. al. raised a serious issue related to synthesis and stability of these NPs [44].

Such as surface charge densities, size dependent reactivity and many other applicable properties can be obtained from particles having diameter below $30 \mathrm{~nm}$ with clean surfaces, It shows need to develop a synthesis method which can give stabile NPs below $30 \mathrm{~nm}$, narrow particle size distribution and surfaces free from organic compounds [31].

In this work, in order to achieve these specifications in $\mathrm{Ag}$ and Al NPs, we have devised a new synthesis approach for synthesis of these NPs using thin films deposited through vacuum thermal evaporation technique under highly controlled experimental conditions and their ultrasonication. The main importance of this work is, the deposited thin films have been per-defined well known thickness, which was precisely known during deposition, which allows constraining at least one dimension of synthesized NPs equal to or below the size of deposited film. Important factor affecting nano particle size is deposition rate, at very low deposition rates evaporation and deposition are occurs at atomic level, resulted in low density high porous film, where the atoms and particles were loosely bound in the film. If the deposited film removes immediately after deposition particles in films not got enough time to set permanently, hence they can easily be re-disperse through ultra-sonication. These controlled experimental conditions, method of deposition, ultrasonication and characterization of synthesized NPs is discussed in this paper. In addition to this, we have also shown the applicability of these NPs for preparation of nanocomposite polymer membranes, which show excellent activity against bio film formation.

The manuscript deals with an innovative approach for synthesis of $\mathrm{Ag}$ and $\mathrm{Al}$ nanoparticles, Where $8 \mathrm{~nm} \mathrm{Ag}$ and Al thin films deposited using thermal evaporation deposition has been dissociated using ultra-sonic method to get very narrow particle size distribution, very small in size and particles surface free from organic capping agents of synthesized Ag and Al NPs. To the best of our knowledge and based lecture review first time we have used this method for synthesis of any NPs. Both the NPs show good antibacterial activity. These Ag and Al NPs were further used for synthesis of nanocomposite with PMMA and identified their properties for bacterial resist film formation that can be directly applicable for synthesis of urine storage bags, blood purification systems \& bags, covers for wound, artificial skin and many other biomedical devices. 


\section{Experimental}

Synthesis of Ag and Al nanoparticles (NPs)

$\mathrm{Ag}$ and Al NPs were synthesized under controlled experimental conditions by thermal evaporation technique following the procedure as described. For deposition, optical grade Ag (99.9\% high purity metals basis) and $\mathrm{Al}$ (99.99\%, high purity metals basis) were purchased from Alfa Asear. Ag and Al thin films were deposited on glass beaker separately using thermal evaporation technique using HINDHI Vacuum coating unit. Spacing between target and substrate was fixed at $10 \mathrm{~cm}$ and working pressure was maintained at $10^{-6}$ torr. Films of $8 \pm 0.1 \mathrm{~nm}$ thickness were deposited with deposition rate of $2 \mathrm{~A} / \mathrm{s}$ controlled by quartz crystal thickness optical monitor. Beakers were removed immediately from the chamber once the deposition was completed and the deposited films in glass beakers were then allowed to dissolve in acetone, under vigorous stirring for 15 minutes at room temperature and then the solutions were dispersed through high frequency ultra-sonication for 1 hour to convert nano thin films into NPs. Now these as-prepared NPs were studied in terms of structural, optical and anti-bacterial properties.

\section{$X$-ray diffraction $(X R D)$}

Phase and particle size of the synthesized Ag and Al NPs were obtained using X'Pert Pro X-ray diffractometer (PAN alytical BV, The Netherlands) operated at a voltage of 45 $\mathrm{kV}$, current $40 \mathrm{~mA}$ and $\mathrm{Cu} \mathrm{k}(\alpha)$ radiation of $1.54059 \AA$ wavelength. Scanning was done in region of $2 \theta$ from $20^{\circ}$ to $70^{\circ}$ with a step size $=0.02^{\circ}$ and time per step $=1.60$ second. Powder sample for XRD was prepared, by drying of acetone suspended Ag and Al NPs solutions. Particle sizes were determined by Scherrer's formula [45]. Crystalline phases were determined using Powder-X and highscore plus software [46].

\section{Transmission electron microscope (TEM)}

SPI, Tecnai, TEM was used to determine the size, shape and size distribution of NPs. Samples were prepared by placing a drop of working solution on a carbon-coated standard copper TEM grid (300 mesh) operating at $200 \mathrm{kV}$. Scanning electron microscope (SEM) and Energy

\section{dispersive X Ray Analysis (EDAX)}

Particle size and morphology of Ag and Al NPs were obtained by SEM while chemical analysis was done with EDAX. SEM analysis was done using Carl ZEISS EVOR 18 operated at $15 \mathrm{kV}$. Sample for SEM and EDAX analysis were prepared on a Si substrates [47]. Few drops of stable particle dispersion of $\mathrm{Ag}$ and $\mathrm{Al}$ were loaded on different Si substrates separately and dried. EDAX measurement of $\mathrm{Ag}$ and Al NPs were performed on same SEM instrument equipped with an Oxford instrument nano analysis $\mathrm{X}$-act EDAX attachment.

\section{ICP-MS (Inductively Coupled Plasma-Mass spectrometer)}

An XSeries ${ }^{\text {II }}$ Quadrupole ICP-MS (Thermo Electron Corporation) was used for the chemical analysis. Sample solution was introduced by continuous nebulization with flow measured PVC pump tube and quartz $\mu$ flow concentric nebulizer [48]. For plasma generation in plasma torch (Quartz glass torch, $1.5 \mathrm{~mm}$ inj.) and other applications Ar gas (99.999\%) was used. To ensure a good wide dynamic range of pulse counting and analogue modes of detector, mass calibration and detector calibration were performed before each analysis and the instrument was optimized by tuning.

\section{UV-Vis Spectroscopy and Photoluminescence (PL) Study}

UV-Vis spectral analysis was done using a double beam UV-Vis spectrophotometer (UV-1800 ENG240V SOFT SHIMADZU) and PL emission spectra was recorded by (RF5301 PL SHIMADZU) Spectro flurometer. Few drops of the synthesized stable particle dispersion of $\mathrm{Ag}$ and $\mathrm{Al}$ NPs were dried and re-dispersed in Milli-Q water then used for UV-Vis and PL analysis.

Antibacterial Study: Zone of inhibition \& Spectrophotometer Analysis

Gram positive E. coli bacteria strain was cultured in Luria Bertani broth (LB broth) and a stock was prepared. To pick a single cell colony \& attain $10^{3} \mathrm{CFU}$, serial dilution of stock was performed. Streaking of this serially diluted culture was done on petri plates and after 24 hours of incubation in incubator, single cell colony was put for culture in LB broth for next 24 hours in incubator. Now to investigate the antibacterial activity of $\mathrm{Ag}$ and $\mathrm{Al}$ NPs, zone of inhibition \& spectrophotometer analysis methods were followed.

Zone of inhibition method was based on visualizing the effects of $\mathrm{Ag}$ and $\mathrm{Al}$ NPs on E. coli in solid agar containing media on petri plates. For this, the spreading method was used and sterilized discs dipped in different concentration (50 ppm, $200 \mathrm{ppm}, 500 \mathrm{ppm}$ ) of $\mathrm{Ag}$ and $\mathrm{Al}$ NPs solutions for 20 minutes were placed on petri plates. These petri plates were incubated for 12 hours. Photomicrograph for inhibited bacteria zone was recorded at $40 \mathrm{x}$ optical magnification by Labomed (T250L250) microscope.

Spectrophotometer Analysis method is based on getting the quantitative data of antibacterial activity shown by Ag and Al NPs. $5 \mathrm{ml}$ LB media was inoculated with single cell colony culture and incubated for 24 hours; then $\mathrm{Ag}$ and $\mathrm{Al}$ NPs, having different concentrations $(50$ ppm, 200 ppm \& $500 \mathrm{ppm}$ ), were added into it and antibacterial properties were obtained through spectrophotometer.

\section{Test for bacterial resist film formation}

Polymer membranes are receiving great interest for synthesis of antibacterial (bacteria free) surfaces, antibacterial coatings, urine storage bags, blood purification systems \& bags, environment protection \& preservation, covers for wound, artificial skin and many other biomedical applications. To assimilate polymer membranes for all these applications, the membranes require high antibacterial and antimicrobial activity. Small addition of synthesized NPs to polymers can improve 
bacteria killing efficiency i.e. antibacterial and antimicrobial activity of the polymers membranes. Hence to study the antibacterial properties of $\mathrm{Ag} \& \mathrm{Al}$ nanocomposite polymer membranes, we had prepared Ag and $\mathrm{Al}$ nanocomposite polymer membranes using synthesized NPs and polymethyl methacrylate (PMMA) as described by Agrawal et. $\mathrm{al}^{20,28}$.

Membranes containing $0.1,0.5$ and 1 weight $\% \mathrm{Ag}$ and $\mathrm{Al}$ NPs were prepared. A membrane was prepared with only PMMA to be used as a control. Nutrient agar (autoclaved) media were speared on each autoclaved membrane. Standard E. coli inoculums were prepared by the method as described by Agrawal et. al. ${ }^{28}$ having E. coli $(\approx 115$ $\mathrm{cfu} / \mathrm{mL})$. Few $\mathrm{ml}$ of this E. coli inoculum was speared on agar media containing membranes. These membranes were kept at $37^{\circ} \mathrm{C}$ in incubation chamber (i.e. favorable condition for bacteria growth). Optical density was recorded after every two hours using spectrophotometer to study bacteria killing efficiency of $\mathrm{Ag}$ and $\mathrm{Al}$ nanocomposite polymer membranes.

\section{Results and discussion}

\section{$X R D$}

Fig. 1 (a) \& (b) show XRD patterns of as synthesized Ag and Al NPs, showing the crystalline nature of NPs. XRD peaks of Ag NPs at $2 \theta$ angles $38.043^{\circ}, 44.265^{\circ}$ and $64.250^{\circ}$, revealing face centered cubic (FCC) crystalline structure with lattice parameter $\mathrm{a}=\mathrm{b}=\mathrm{c}=4.092 \AA$, were identified as (111), (200) and (220) crystalline planes respectively (JCPDS file No. 00-004-0783). Similarly XRD peaks of Al NPs at $2 \theta$ degrees of $38.535^{\circ}, 44.726^{\circ}$ and $65.140^{\circ}$, revealing the face centered cubic (FCC) crystalline structure with lattice parameter $\mathrm{a}=\mathrm{b}=\mathrm{c}=4.0538$ $\AA$, were identified as (111), (200) and (220) crystalline planes respectively (JCPDS file No. 85-1327). The broadening in the diffraction peaks of XRD pattern of $\mathrm{Ag}$ and Al NPs is attributed to the nanometer-sized crystallites. The average particle size of these synthesized $\mathrm{Ag}$ and $\mathrm{Al}$ NPs, as calculated using the Debye-Scherrer's relation ${ }^{31}$, was about $22 \mathrm{~nm}$ and $13 \mathrm{~nm}$ respectively.
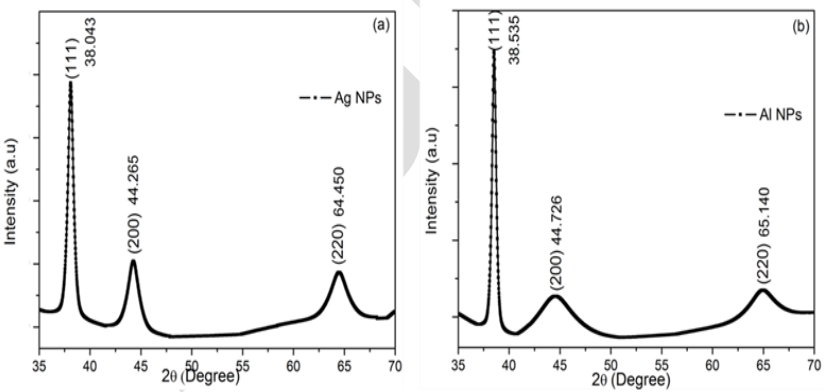

Fig. 1. X-ray diffraction pattern of Ag and Al NPs synthesized by ultrasonic dissociation of thermally deposited thin films. Crystalline phase and corresponding reflection at $2 \Theta$ is also marked at top of peaks, with reference to diffraction data from JCPDS files for Ag NPs (No. 00-0040783) and Al NPs (No. 00-004-0783). Average particle comes out to be 22 and $13 \mathrm{~nm}$ for $\mathrm{Ag}$ and $\mathrm{Al}$ NPs respectively.

\section{TEM}

Shape and size distribution of these self-suspended nanoparticles were characterized by Transmission Electron
Microscopy (TEM) after 1 hour of Ultra-sonication of the samples. Fig. 2 (a) \& 2 (c) show TEM images of Ag NPs having particle size ranging from 20 to $30 \mathrm{~nm}$ and fig. $2 \mathrm{~b}$ \& 2d show TEM images of Al NPs with particle size ranging from 8 to $13 \mathrm{~nm}$. All these images show that the samples/particles have uniform, small particle size distribution with uniquely dispersed particles. In images, individual grain/nanoparticle boundary can be easily identified, showing no agglomeration of particles. The Same particle size was also shown by X-ray diffraction.

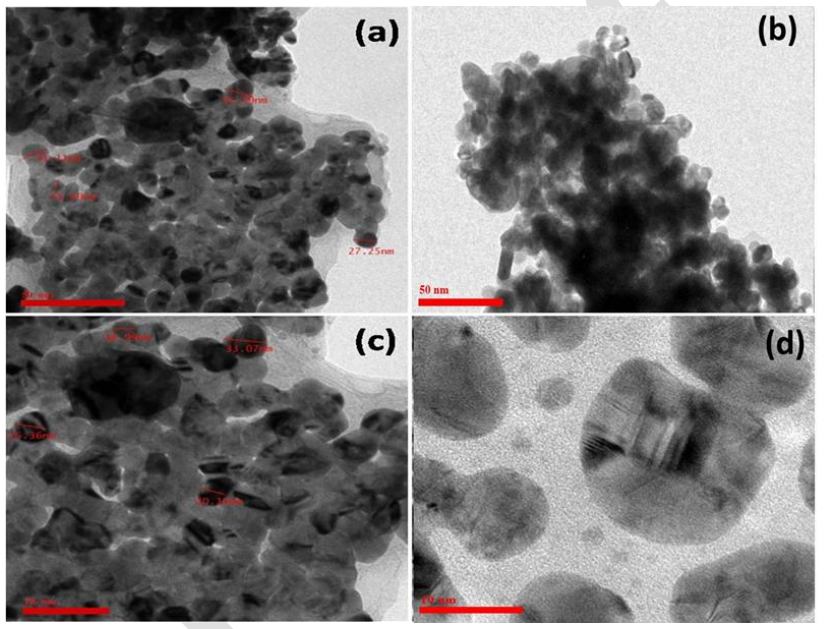

Fig 2. Transmission electron micrographs (TEM) of Ag and Al NPs synthesized by ultra-sonic dissociation of thermally deposited thin films. (a) Ag NPs at $50 \mathrm{~nm}$ scale, (b) Al NPs at $50 \mathrm{~nm}$ scale, (c) Ag NPs at 10 $\mathrm{nm}$ scale and (d) Al NPs at $10 \mathrm{~nm}$ scale.

\section{SEM and EDXA}

For the present analysis, XRD pattern and TEM images are the best indicators of particle size and phase of NPs. But to understand, the conversion of thin films into NPs i.e. the mechanism of dissociation of films with time of ultrasonication and to identify presence of any type of impurity with the NPs were obtained by SEM and EDAX. To avoid gold coating on samples, samples were prepared on conducting $\mathrm{Si}$ substrates. Few drops of stable particle dispersion of $\mathrm{Ag}$ and $\mathrm{Al}$ NPs were loaded on different $\mathrm{Si}$ substrates after 15 minutes and 1 hour ultra-sonication and allowed to dry at room temperature. The Fig. 3(a) \& (c) show the SEM images of Ag NPs after 15 minutes \& 1 hour ultra-sonication respectively, with final particle size ranging from 25 to $35 \mathrm{~nm}$. Such as Fig. 3 (b) \& (d) shows the SEM images of Al NPs after 15 minutes \& 1 hour ultra-sonication respectively, with final particle size ranging from 10 to $15 \mathrm{~nm}$. The presence of pieces of thin films in Fig. 3(a) \& (b), were clearly shown the film dissociation process and the starting of formation of NPs, as well as the thickness of deposited films $8-10 \mathrm{~nm}$ in each case can also be easily identified (Fig. 3(a) \& (b), it must be noted here that films of $8 \mathrm{~nm}$ were deposited for both $\mathrm{Ag}$ and $\mathrm{Al}$ as monitored by thickness meter during deposition of thin films) but it also show that 15 minutes ultra-sonication time was insufficient for conversion of films into NPs. While Fig. 3(c) \& (d) show Ag and Al NPs after 1 hour of ultra-sonication of samples, from these images we can conclude that 1 hour is sufficient time for ultra-sonication to convert the deposited films into NPs and 
more time for ultra-sonication does not show much improvement. Fig 3e \& 3f show EDAX analysis of Ag and Al NPs respectively. As EDAX analysis was performed on $\mathrm{Si}$ substrate, hence it shows highest signal for $\mathrm{Si}$, but no signal other than $\mathrm{Ag}$ and $\mathrm{Al}$ are present, which shows the purity of synthesized NPs.

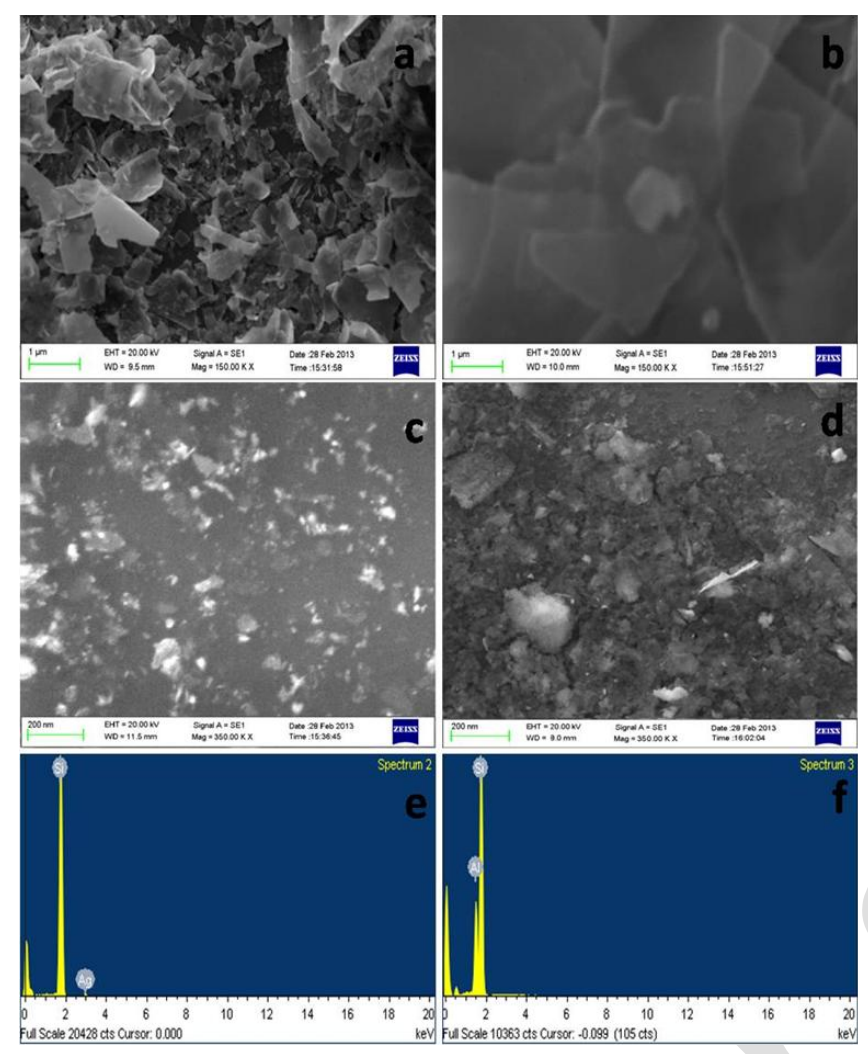

Fig. 3. Scanning electron micrographs (SEM) of $\mathrm{Ag}$ and $\mathrm{Al}$ NPs synthesized by ultra-sonic dissociation of thermally deposited thin films. (a) Ag NPs after 15 min ultra-sonication, (b) Al NPs after 15 min ultrasonication, (c) Ag NPs after 1 hrs ultra-sonication, (d) Al NPs after 1 hrs. ultra-sonication. Whereas, (e) \& (f) are EDAX analysis for the synthesized $\mathrm{Ag}$ and Al NPs.

\section{Chemical Characterization by ICP-MS (Inductively}

\section{Coupled Plasma-Mass spectrometer):}

ICPMS measurements were performed for chemical/elemental analysis of the synthesized NPs. These NPs were brought into solution form by chemical dissolution in $\mathrm{HNO}_{3}$ for ICPMS measurement. ICPMS Signal to concentration conversion was done using standard calibration method [49-52]. Table 1 lists the elemental abundances of NPs, with almost negligible amount/concentration of others elements, which shows the purity of synthesized NPs.

\section{UV-Vis Spectroscopy}

Different sizes and shapes significantly affect the optical properties of any nanomaterial which are sometimes markedly different form the corresponding bulk material. We were determined the optical properties using UV-Vis and PL spectroscopy.

UV-visible absorption spectra of Ag and Al NPs, taken immediately after synthesis, is shown in Fig. 4 (a), while fig. $4 \mathrm{~b}$ shows the band gap of the synthesized NPs, obtained using tauc relation $\left[\alpha \mathrm{h} v=\mathrm{K}\left(\mathrm{h} v-\mathrm{E}_{\mathrm{g}}\right)^{\mathrm{n}}\right]$, where $\mathrm{K}$ is a constant relative to material, hv is photon energy, $\alpha$ is the absorption, $\mathrm{E}_{\mathrm{g}}$ is the band gap of material and $\mathrm{n}$ depends on nature of transitions and may have values $1 / 2,2,3 / 2$ and 3 corresponding to allowed direct, allowed indirect, forbidden direct and forbidden indirect transitions respectively. Ag and $\mathrm{Al}$ show direct allowed transition, hence $n=1 / 2$ used [31]. $E_{g}$ for NPs is determined by extrapolating $(\alpha h v)^{2}$ vs hv at zero absorption coefficient.

UV-Vis absorption band edges are observed at $3.81 \mathrm{eV}$ for Ag NPs and $3.70 \mathrm{eV}$ for Al NPs. As no clear SPR peak (Surface Plasmon Resonance) is occurring (fig 4a), hence SPR was calculated from the band gap using $\left(\lambda=\mathrm{hc} / \mathrm{E}_{\mathrm{g}}\right)$ which comes out to be $325 \mathrm{~nm}$ and $335 \mathrm{~nm}$ for $\mathrm{Ag} \& \mathrm{Al}$ NPs respectively.

Table 1. Concentration of different elements presents in synthesized Ag and Al NPs.

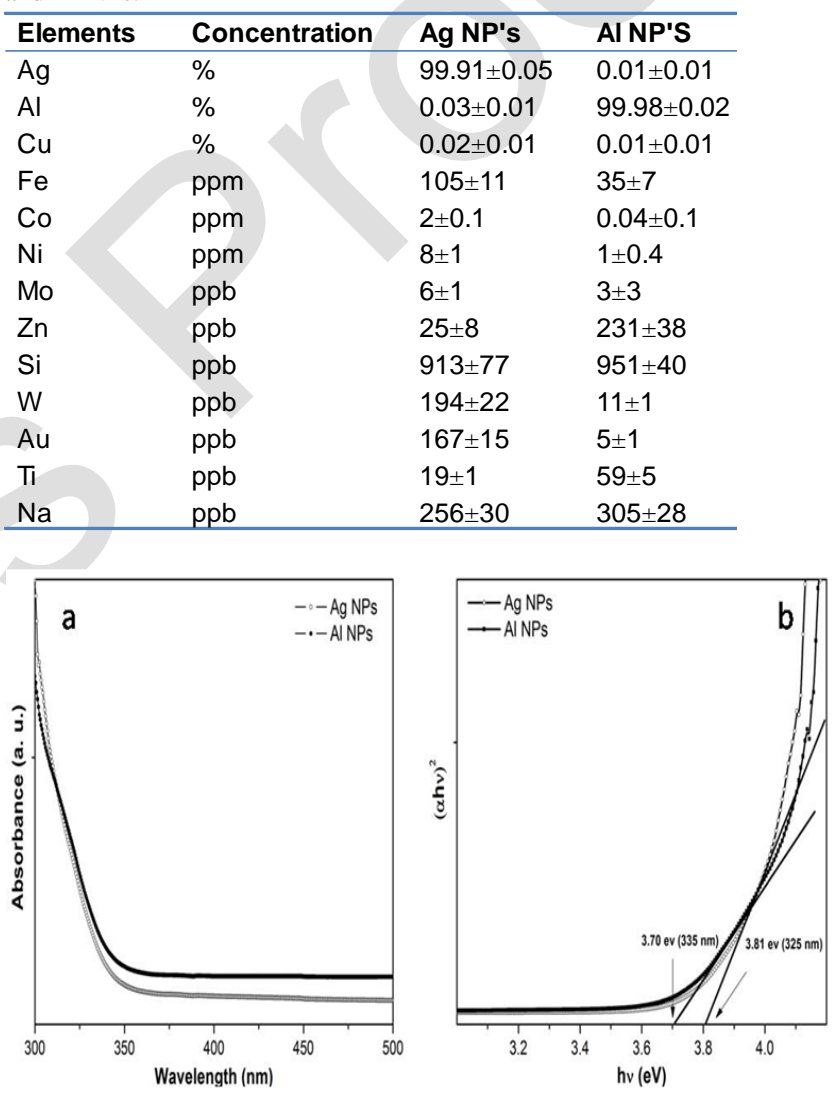

Fig. 4. UV-Vis absorption spectrum and spectrum obtained using tauc relation for the synthesized Ag and Al NPs.

\section{Photoluminescence Study}

Photoluminescence (PL) emission spectra of $\mathrm{Ag}$ and $\mathrm{Al}$ NPs are shown in Fig. 5. PL emission spectra were recorded at selected excitation wavelength of $330 \mathrm{~nm}$, which is average maximum SPR value for Ag and Al NPs. A broad PL emission band occurs ranging from 335 to 525 $\mathrm{nm}$ centered at $\lambda_{\max } 391 \mathrm{~nm}$ with calculated luminescence energy gap value $3.17 \mathrm{eV}$ for Ag NPs. Al NPs show broad PL emission band ranging from 342 to $560 \mathrm{~nm}$ centered at $\lambda_{\max } 396 \mathrm{~nm}$ with calculated luminescence energy gap value $3.13 \mathrm{eV}$, which corresponds to direct recombination between electrons in conduction band and holes in the valence band. 


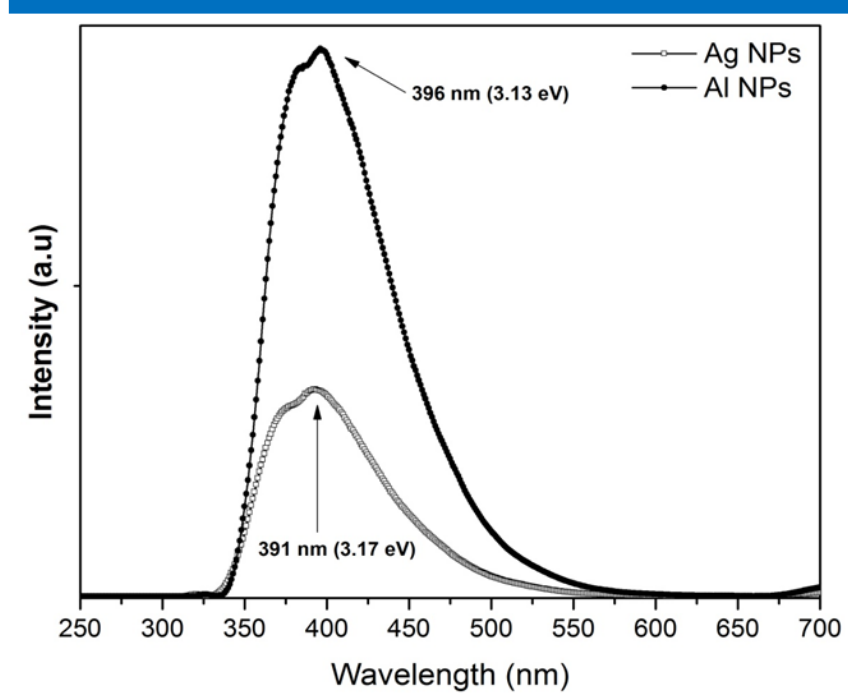

Fig. 5. Photoluminescence (PL) emission spectra of the synthesized Ag and Al NPs.

\section{Antibacterial Study}

Fig. 6 shows zone of inhibition for $\mathrm{Ag}$ and $\mathrm{Al}$ NPs. It is clear from the images that Ag NPs are more potent than $\mathrm{Al}$ NPs, as diameter of zone of inhibition of Ag NPs is far bigger than Al NPs for all concentrations which remarkably demonstrates the better antibacterial properties of Ag NPs as compared to Al NPs. Micrographs recorded at $40 \mathrm{x}$ magnification show same nature of anti-bacterial properties.

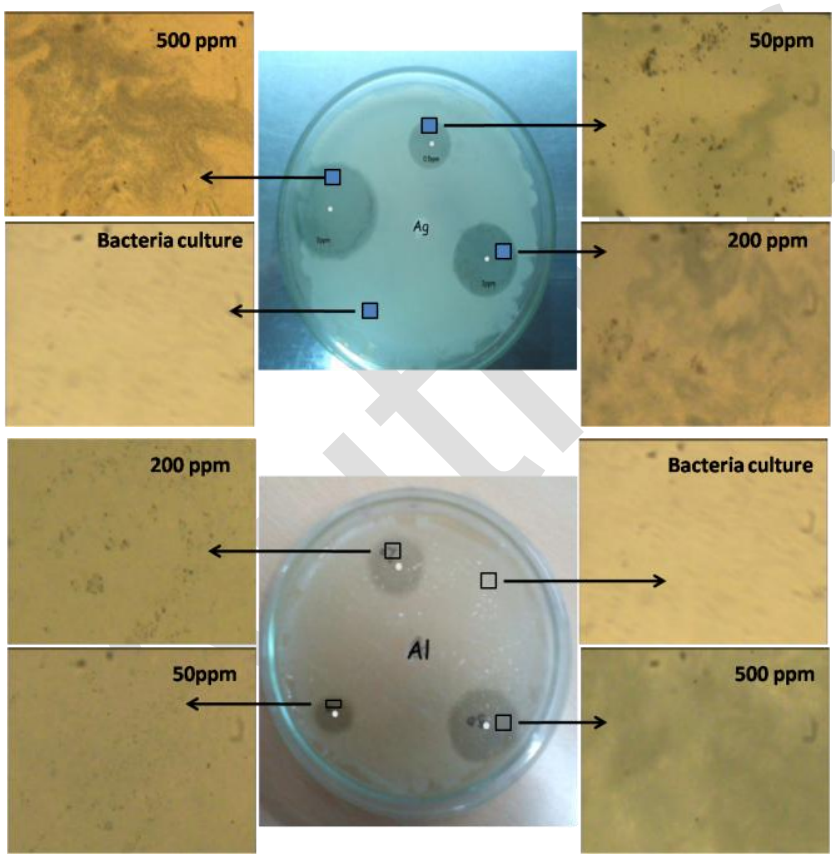

Fig. 6. Study of antibacterial properties of synthesized Ag and Al NPs by zone of inhibition method and enlarged micrographs of inhibition are showing potent activity of NPs.

Same facts are observed by the spectrophotometer test of optical density (OD) of bacterium culture treated with $\mathrm{Ag}$ and Al NPs and the results are shown in table 2. OD results also confirm that Ag NPs show high anti-bacterial activity compared to Al NPs.
Table 2. Spectrophotometer optical density analysis for synthesized NPs against E. coli bacteria.

\begin{tabular}{lll}
\hline $\begin{array}{l}\text { Concentration } \\
\text { of NPs }\end{array}$ & Ag NPs & Al NPs \\
\hline $50 \mathrm{ppm}$ & -0.068 & -0.048 \\
$200 \mathrm{ppm}$ & -0.079 & -0.061 \\
$500 \mathrm{ppm}$ & -0.098 & -0.074 \\
\hline
\end{tabular}

\section{Applicability of the Ag \& Al NPs in bacterial resist film}

\section{formation}

The effect of these $\mathrm{Ag} \& \mathrm{Al}$ NPs on bacterial resist film formation/surface sterilization was determined by measuring the optical density after every two hours, using spectrophotometer. Fig. 7 shows percentage bacteria survival or bacterial growth on samples, calculated with respect to the initial concentration of bacteria on membranes. As we kept membranes in favorable conditions for bacteria growth, a 3\% growth of bacteria per hour for PMMA membrane was found, which shows formation of bio/bacterial film on pristine membranes. But for PMMA membranes having Ag and Al NPs negative bacteria growth was found i. e. bacteria got killed when they have an interaction with these nanocomposite membranes.

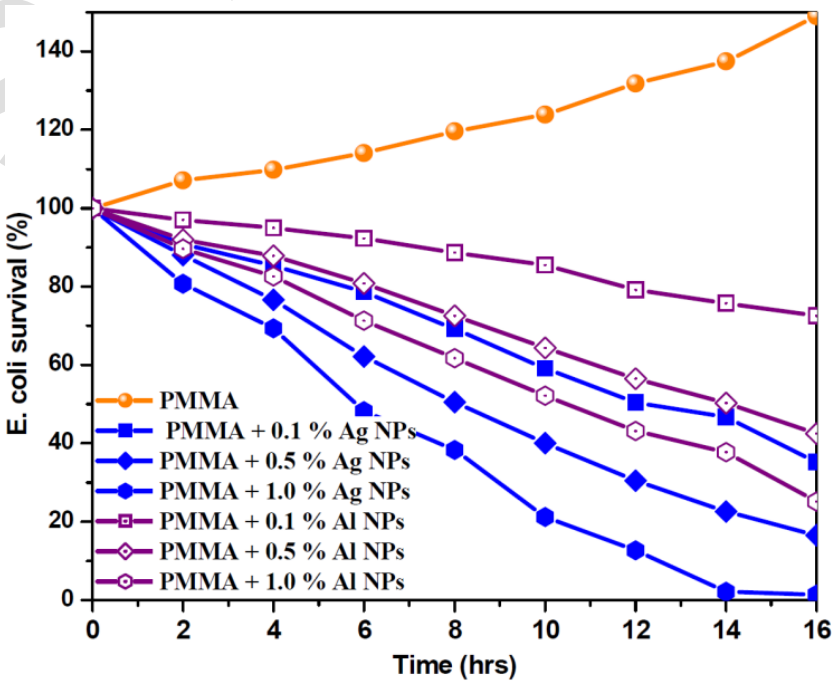

Fig. 7. Efficiency of bacterial survival on $\mathrm{Ag}$ and $\mathrm{Al}$ nanocomposite polymer membranes applicable in bacterial resist films formation or bacteria-sterilization.

Here also Ag nanocomposite membranes are more potent than $\mathrm{Al}$ nanocomposite membranes. 0.1, 0.5 and 1.0 $\% \mathrm{Ag}$ nanocomposite membranes show bacteria growth rate of $-3.75,-5.00$ and $-6.25 \%$ per hour respectively and almost all the bacteria were got killed after 16 hour in case of $1.0 \% \mathrm{Ag}$ nanocomposite membrane; while $0.1,0.5$ and $1.0 \% \mathrm{Al}$ nanocomposite membranes show bacteria growth rate of $-1.86,-3.12$ and $-4.68 \%$ per hour respectively i.e. both nanocomposite membranes can be used for formation of sterilized surfaces (Fig. 7). Typical sterilization efficiency of these nanocomposite membranes makes them suitable for synthesis of bacteria free surfaces for clinical purposes as the amount of bacteria in environment is very 
less than the bacterial culture $(\approx 115 \mathrm{cfu} / \mathrm{mL})$ used here. Present analysis also shows the applicability of these membranes and NPs for synthesis of urine storage bags, blood purification systems \& bags, covers for wound, artificial skin and other biomedical devices, where high self-sterilization efficiency of surfaces are needed.

\section{Conclusion}

$>$ In the present study, we have synthesized $\mathrm{Ag}$ and $\mathrm{Al}$ NPs by using an innovative approach of dissociation of thermal deposited thin films, having clean surfaces free from organic capping agents to be used in future interfacial studies. Here the demonstrated synthesis method was extremely simple, cheaper and fast for synthesis of NPs without generating any toxic byproduct in addition to having small particle size and narrow particle size distribution.

$>22 \mathrm{~nm}$ and $13 \mathrm{~nm}$ were the average particle diameters obtained by XRD analysis for Ag and Al respectively. Similar results were also observed in TEM and SEM analysis where the particle sizes ranged from 20-30 $\mathrm{nm}$ and 8-13 $\mathrm{nm}$ obtained for $\mathrm{Ag}$ and $\mathrm{Al}$ NPs respectively. These analyses show no agglomeration in particles even when synthesized without using any capping/stabilizing agents.

$>$ EDAX and ICPMS show chemical analysis of NPs and prove purity of the synthesized NPs.

$>$ UV- Vis absorption band edges (SPR) were observed at $3.81 \mathrm{eV}(325 \mathrm{~nm})$ and $3.70 \mathrm{eV}(335 \mathrm{~nm})$ for $\mathrm{Ag}$ and Al respectively, while $\mathrm{PL}$ emission were observed at $391 \mathrm{~nm}$ and $396 \mathrm{~nm}$ respectively for excitation at 330 nm.

$>$ These Ag and Al NPs both showed antibacterial properties against E. coli bacteria, but Ag NPs were found more potent than Al NPs, which was determined by both micrograph images and OD test.

$>\quad$ These Ag and Al NPs were further used for synthesis of nanocomposite polymer membranes with PMMA. These membranes showed excellent efficiency for killing bacteria to be used for bacterial resist films formation or bacteria-sterilization.

Further the study can be extended for other NPs with variable thickness of deposited film that will help to understand the film dissociation mechanism. The fabricated membranes can be used to test their biological response towards blood cells and blood plasma to identify their possible use in blood storage bags etc.

\footnotetext{
Acknowledgements

Authors are thankful to Mr. Raza of for helping in TEM and SEM measurements. Authors are also thankful for Department of Physics, University of Rajasthan for providing facilities for XRD measurements and USIC, University of Rajasthan for providing facilities for TEM and SEM analysis. Authors are also thankful to Jawaharlal Nehru Memorial Fund, New Delhi, India and INSPIRE DST, New Delhi, India for providing Scholarship to Mr. Narendra Kumar Agrawal and Ravi Agarwal respectively to carry out this work.
}

\section{Reference}

1. Khaydarov, R. R.; Khaydarov, R. A.; Estrin, Y.; Evgrafova, S.; Cho S. Y.; Wagner, S.; Nova Science Publishers: USA. 2003. DOI: $10.1007 / 978-94-007-1235-5$-9.
2. Kim, J. S.; Kuk, E.; Yu, K. N.; Kim, J. H.; Park, S. J.; Lee, H. J.; Kim, S. H.; Park, Y. K.; Park, Y. H.; Hwang, C. Y.; Kim, Y. K.; Lee, Y. S.; Jeong, D. H.; Cho, M. H.; Science Direct 2007, 3, 95.

DOI: $10.1016 /$ j.nano.2006.12.001

3. Farkasa, J.; Christian, P.; Urrea, J. A. G.; Roos, N.; Hassellöv, M.; Tollefsen K. E.; Thomas, K. V.; Aquatic Toxicol. 2010, 96 (1), 44 DOI: $10.1016 /$ j.aquatox.2009.09.016.

4. Ahameda, M.; AlSalhia, M. S.; Siddiquib, M. K. J.; Clinica Chimica Acta 2010, 411 (23-24), 1841.

DOI: $10.1016 /$ j.cca.2010.08.016.

5. Shrivastava, S.; Bera, T.; Singh, S. K.; Singh, G.; Ramachandrarao P.; Dash, D.; ACS Nano 2009, 3(6) 1357.

DOI: $\underline{10.1021 / \mathrm{nn} 900277 \mathrm{t}}$.

6. Wagner, A. J.; Bleckmann, C. A.; Murdock, R. C.; Schrand, A. M.; Schlager J. J.; Hussain, S. M.; J. Phys. Chem. B 2007, 111, 7353. DOI: $10.28 ; 111(25): 7353-9$.

7. Agarwal, P.; Mehta, A.; Kachhwaha S.; Kothari, S. L.; Adv. Sci. Eng. Med. 2013, 5(7), 709 .

DOI: $10.1166 /$ asem.2013.1307

8. Oehr, C.; Ionizing Radiation and Poly. 2003, 208, 40. DOI: $10.1016 / \mathrm{S} 0168-583 \mathrm{X}(03) 00650-5$

9. Vijay, Y. K.; Acharya, N. K.; Wate, S.; Avasthi, D. K.; Int. J. Hydrogen Energy. 2003, 28, 1015. DOI: $\underline{10.1016 / \mathrm{S} 0360-3199(02) 00166-0}$

10. Sunada, K.; Watanabe, T.; Hashimoto, K.; J. Photochem. and Photobio. A: Chem. 2003, 156, 227.

DOI: $10.1016 / \mathrm{S} 1010-6030(02) 00434-3$

11. Chua, P. K.; Chena, J. Y.; Wanga, L. P.; Huang N.; Mater. Sci. Eng. 2002, 36, 143. DOI: $10.1016 / \mathrm{S} 0927-796 \mathrm{X}(02) 00004-9$

12. Yu, S.; Liu, X.; Liu, J.; Wu, D.; Liu, M.; Gaoc, C.; Separation and Purification Technol. 2011, 76, 283. DOI: $10.1016 /$ j.seppur.2010.10.017

13. Bagra, B.; Pimpliskar, P.; Agrawal, N. K.; AIP Conf. Proc. 2014, 1591, 189.

DOI: $10.1063 / 1.4872539$

14. Gao, L.; Zhang, Q. H.; Scripta Mater. 2001, 44, 1195. DOI: $10.1016 / \mathrm{S} 1359-6462(01) 00681-9$

15. Mohammadia, M. R.; Fray, D. J.; Cordero-cabrera, M. C.; Sensor. \& Actua. B, Chem. 2001, 124, 74. DOI: $\underline{10.1016 / \text { j.snb.2006.11.048 }}$

16. Agarwal, R.; Agrawal, N. K.; Singh, R.; Mater. Focus 2014, 3, 267. DOI: $10.1166 /$ mat.2014.1177

17. Baylay, H.; Jayasinghe, L.; Mol Membr Biol. 2004, 21, 209. DOI: $\underline{10.1080 / 09687680410001716853}$

18. Kedawat, G.; Gupta, B. K.; Kumar, P.; Dwivedi, J.; Kumar, A.; Agrawal, N. K.; Kumar, S. S.; Vijay, Y. K.; ACS Appl. Mater. Interfaces, 2014, 6(11), 8407. DOI: $10.1021 / \mathrm{am} 501307 \mathrm{~h}$

19. Khandelwal, S.; Kumar, G. A.; Agarwal, R.; Agrawal, N. K.; Int. J. Eng. Res. Technol. 2014, 1, 98 DOI: $10.13140 / 2.1 .3042 .9766$

20. Gomathi, N.; Sureshkumar, A.; Neogi, S.; Current Sci. 2004, 90, 148. DOI: $10.1002 / a p p .30691$

21. Agrawal, N. K.; Agarwal R.; Vijay Y. K.; Swami K. C.; J. Mat. Sci. Surf. Eng. 2013, 1(1), 4.

22. Ramalingam, M.; Tiwari, A. Adv. Mat.Lett. 2010, 1, 179. DOI: 10.5185 /amlett.2010.9160

23. Goyal, A.; Sharma, V.; Sharma, A.; Agarwal, R.; Sharma, K. B.; Kothari, S. L.; J. Nano-and Electronic Phys. 2011, 3(1), 254. DOI: $\underline{\text { 81.05.Dz81.07.Bc81.16.Be }}$

24. De, S.; Sharma, R.; Ali, N.; Mazumder, M. K.; IEEE 2004, 5, 932. DOI: $\underline{10.1109 / \mathrm{IAS} .2004 .1348524}$

25. Listona, E. M.; Martinub, L.; Wertheimerc, M. R.; J. Adhesion Sci. Technol. 1993, 7, 1091. DOI: $10.1163 / 156856193 \mathrm{X} 00600$

26. Agrawal, N. K.; Agarwal, R.; Vijay, Y. K.; Swami, K. C.; J. Mater Sci. Surf. Eng. 2014, 1(1), 23.

27. Agrawal, N. K.; Agarwal, R.; Vijay, Y. K.; Swami, K. C.; J. Bionanosci. 2014, 8,108 DOI: $10.1166 /$ jbns. 2014.1207

28. Lee, K. M.; Hu, C. W.; Chen, H. W.; Ho, K. C.; Solar Energy Mater. \& Solar Cells 2008, 92, 1628. DOI: $\underline{10.1016 / \mathrm{j} . \text { solmat.2008.07.012 }}$

29. Agrawal, N. K.; Agarwal, R.; Vijay, Y. K.; Swami, K. C.; J. Mater Sci. Surf. Eng. 2014, 1(3), 69. 
30. Agarwal, R.; Agrawal, N. K.; Singh, R.; Adv. Sci. Eng. Med. 2014, 6 (2), 203.

DOI: $10.1166 /$ asem.2014.1474

31. Wang, Y. Q.; Zhang, H. M.; Wang, R. H.; Coll. Surfaces B: Biointerf. 2008, 65, 190

DOI: $10.1016 /$ j.colsurfb.2008.04.001

32. Agrawal, N. K.; Awasthi, K.; Vijay, Y. K.; Swami, K. C.; Adv. Electrochem. 2013, 1 (2), 98.

DOI: $10.1166 /$ adel.2013.1017

33. Agrawal, N. K.; Singh, M.; Vijay, Y. K.; Swami, K. C.; Adv. Sci. Eng. Med. 2014, 6(5), 595 .

DOI: $10.1166 /$ asem.2014.1535

34. Saxena S.; Dubey, R.; $A d v$. Sci. Eng. Med. 2014, 6, 704 DOI: $10.1166 /$ asem.2014.1564

35. Agrawal, N. K.; Agarwal, R.; Vijay, Y. K.; Swami, K. C.; Adv. Sci. Eng. Med. 2014, 6(6), 698 .

DOI: $10.1166 /$ asem.2014.1565

36. Pimpliskar, P.; Bagra, B.; Gautam, A. K.; Khandelwal, S.; Agrawal, N. K.; AIP Conf. Proc. 2014, 1591, 481.

DOI: $10.1063 / 1.4872646$

37. Langford, J. I.; Wilson, A. J. C.; J. Appl. Crystall. 1978, 11, 102. DOI: $10.1107 / \mathrm{S} 0021889878012844$

38. Agrawal, N. K.; Agarwal, R.; Vijay, Y. K.; Swami, K.C.; J. Mater. Sci. Surf. Eng. 2014, 1(2), 32

39. Wagnera, E. M. V.; Saglea, A. C.; Sharmab, M. M.; Lac, Y. H.; Freemana, B. D.; J. Membrane Sci. 2011, 367, 273.

DOI: $10.1016 /$ j.memsci.2010.11.001

40. Sairam, M.; Patil, M. B.; Veerapur, R. S.; Patil, S. A.; Aminabhavi, T. M.; J. Membrane Sci. 2006, 281, 95. DOI: $10.1016 /$ j.memsci.2006.03.022

41. Ma, G. Q.; Liu, X. N.; Huang, D. H.; Yuan, X. B.; Sheng, J.; Appl. Surface Sci. 2009, 255, 7483.

DOI: $10.1016 /$ j.apsusc. 2009.03.066

42. Rundell, V.L.M.; Beck, R.T.; Wang, C.E.; Gutowski, K.A.; Sisco, M.; Fenner, G.; Howard, M.A.; J. Plastic, Reconstructive \& Aesthetic Surg. 2014, 16, 32.

DOI: $10.1016 /$ j.bjps.2014.05.032.

43. Wang, Y.; Marshall, K. L.; Baba, Y.; Gerling, G. J.; Lumpkin, E. A.; PLOS ONE 2013, 8(6), 67439.

DOI: 10.1371 /journal.pone.0067439.

44. Edwards, M. B.; Mclean, J.; Solomonidis, S.; Condon, B.; Gourlay, T.; J. Magnet. Resonance Imaging. 2013, 62, 1452. DOI: $10.1002 / \mathrm{jmri} .24547$.

45. Smith, R. S.; Zhang, Z.; Bouchard, M.; Li, J.; Lapp, H. S.; Brotske, G. R.; Lucchino, D. L.; Weaver, D.; Roth, L. A.; Coury, A.; Biggerstaff, J.; Sukavaneshvar, S.; Langer, R.; Loose, C.; Sci. Transl. Med. 2012, $4,153$.

DOI: $10.1126 /$ scitranslmed.3004120

46. Meziani, M. J.; Bunker, C. E.; Lu, F.; Li, H.; Wang, W.; Guliants, E. A.; Quinn R. A.; Sun, Y. P.; Appl. Mater. Interf. 2009, 1(3), 703. DOI: $10.3390 /$ amis 111110691

47. Agrawal, N. K.; Agarwal, R.; Awasthi, K.; Vijay, Y. K.; Swami, K. C.; Adv. Mat. Lett. 2014 5(11), 645 DOI: $10.5185 /$ amlett.2014.nib502

48. Sadiq, I. M.; Chowdhury, B.; Chandrasekaran N.; Mukherjee, A.; Nanomed. Nanotechnol. Biolo. Medici. 2009, 5(3), 282.

DOI: $10.1015 / \mathrm{nbic} 1254780014$

49. Monteiro-Riviere, N. A.; Oldenburg S. J.; Inman, A. O.; J. Appl. Toxicol. 2010, 30(3), 276

DOI: $10.1016 /$ j.at.2013.08.039

50. Abreu, M. B.; Powell, C.; Raber A. C.; Khanna, S. N.; J. Am. Chem. Soc. 2012, 134(50), 20507.

DOI: $10.1021 / \mathrm{acs} 900327 \mathrm{~b}$

51. Agrawal, N. K.; Study of Enhancement in Bio-Adoptability \& Biocompatibility of Nano Composite Polymer Membranes by Plasma Treatment. Ph. D. Thesis, Malaviya National Institute of Technology, Jaipur, India, 2014.

52. Alshatwi, A. A.; Subbarayan, P. V.; Ramesh, E.; Hazzami, A. A.; Alsaif M. A.; Alwarthan, A. A.; Food Addit. Contamin. A 2013, 30, 1. DOI: $10.1021 /$ facn $502662 p$

\section{Advanced Materials Letters}

Publish your article in this journal

ADVANCED MATERIALS Letters is an international journal published quarterly. The journal is intended to provide top-quality peer-reviewed research papers in the fascinating field of materials science particularly in the area of structure, synthesis and processing, characterization, advanced-state properties, and applications of materials. All articles are indexed on various databases including DOAJ and are available for download for free. The manuscript management system is completely electronic and has fast and fair peer-review process. The journal includes review articles, research articles, notes, letter to editor and short communications. 